\title{
Factors Related to Antiretroviral Therapy Adherence in Children and Adolescents with HIV/ AIDS in Cuba
}

\author{
Marta Castro MD MS, Ida González MD PhD, Jorge Pérez MD MS
}

\begin{abstract}
INTRODUCTION In recent years, global initiatives to address the AIDS epidemic have produced promising advances through access to effective treatment programs. However, lack of adherence to antiretroviral therapy is a problem for pediatric patients.

OBJECTIVE Explore antiretroviral therapy adherence in children and adolescents living with HIVIAIDS in Cuba and examine its relationship with psychosocial, individual and treatment factors.

METHODS A qualitative study was carried out of 21 caregivers of children and adolescents with HIVIAIDS. Demographics and information on treatment regimen were collected by chart review. Indepth interviews were conducted to assess adherence and examine its relationship with psychosocial, individual and treatment factors. Interviews were transcribed and the information was grouped by factor category. Adherence was analyzed in relation to these three sets of factors.
\end{abstract}

RESULTS Caregivers interviewed reported adequate adherence in 17 of the 21 children. Lack of adherence was linked primarily to psychosocial factors such as additional responsibility taken on by the caregiver while grappling with his or her own illness, the presence of untreated psychological symptoms in the caregiver, perceived difficulties with family support, the child's age, and assigning treatment responsibilities to the child without taking into account his/her psychological maturity.

CONCLUSIONS The study revealed a high level of antiretroviral therapy adherence. It reconfirmed the fundamental importance of the caregiver and family support for therapeutic success in children and adolescents living with HIVIAIDS. These results, as well as the factors identified in cases of nonadherence, can contribute to a framework for assessment and specialized interventions to optimize pediatric antiretroviral adherence.

KEYWORDS HIV, AIDS, antiretroviral therapy, patient adherence, patient compliance, patient nonadherence, treatment adherence, treatment compliance, treatment nonadherence, Cuba

\section{INTRODUCTION}

In recent years, promising advances have been made in global initiatives to address the AIDS epidemic, including improved access to effective prevention and treatment programs.[1-3] Development of antiretroviral therapy (ART) drastically modified AIDS mortality rates, resulting in new challenges for patient care. $[1,4]$ These challenges also apply to children with HIVIAIDS, who should become fully incorporated into normal social life while living with a chronic disease.[4]

The adoption of combined therapies, using protease inhibitors and other antiretroviral agents, has been effective in reducing viral load to low or undetectable levels, leading to sustained health improvements in adults and children.[3-7] ART nonadherence is associated with compromised health and disease progression,[2-4] as well as appearance of resistant viral strains.[8]

Multiple efforts are under way to study factors associated with successful ART. Review articles consistently indicate that nonadherence is a problem for both adults and children, and that evidence varies regarding factors related to good adherence. Such factors have been associated with characteristics of the disease and its treatment (regimen, formulation, dose and side effects), social context, socioeconomic conditions, and access to specialized health services.[9-12]

In Cuba, domestically-produced antiretroviral medications are offered free of charge to patients living with HIVIAIDS, and ART coverage has been complete since 2003.[13] However, a study exploring factors related to treatment adherence in adult Cuban patients with HIVIAIDS found that $70 \%$ of patients were compliant. Some of the variables associated with successful adherence were a good doctor-patient relationship, and the patient's commitment to and favorable opinions of treatment.[14]

It has been established that successful adherence requires active patient involvement in decisionmaking, including choice of therapeutic regimen, a process that also involves the health care team as well as family and social support networks. However, it is more complicated to define the factors influencing adherence in children,[15-17] because the child's active participation is mediated by the health care team and the ability of caregivers to be responsible for treatment.

Varying results in adherence are reported in pediatric patients. $[9,10,17,18]$ Estimated ART adherence percentages in studies using caregiver reports have shown a wide variation, from $26 \%$ to $100 \%$ adherence to prescribed treatment.[11,17] Other studies using methods such as tablet counting and pharmacy records of antiretroviral consumption, estimated adherence at rates of $70 \%-89 \%$ and $52 \%-70 \%$, respectively.[19] Blood tests for drug levels and electronic monitoring of doses taken, alone or in combination, have produced lower and probably more valid estimates of actual treatment adherence, $[10,20]$ due to increased sensitivity in detecting nonadherence.

ART adherence in Cuban children with HIVIAIDS has not been adequately explored, nor have the factors that might be related to adherence in these patients. This study aimed to explore ART adherence in children and adolescents living with HIVIAIDS and to examine the associations between adherence and psychosocial, individual and treatment factors.

\section{METHODS}

Design A qualitative study using caregiver interviews, complemented by patient records, was carried out from September to December 2010.

Participants Through intentional sampling,[21] researchers selected 21 primary caregivers of Cuban children and adolescents living with HIVIAIDS who were receiving specialized care 
at Havana's Pedro Kourí Tropical Medicine Institute (IPK). Caregivers were selected if the children and adolescents under their care met the following criteria: receiving ART treatment at the time of the study, 3-16 years of age, and acquired the infection via mother-child transmission, or blood or hemoderivative transfusion.

Adherence Caregiver reports of doses administered were used to assess patient adherence. Interviewers inquired about administration of ART as prescribed during the week prior to the interview, particularly the previous three days. The children and adolescents studied were classified as nonadherent when caregivers reported missing at least two doses in the previous three days or more than four doses in the previous week.

Data collection Clinical histories were reviewed to obtain data on children's and adolescents' characteristics for the variables described in Table 1. Clinical classification was per US CDC criteria for pediatric patients aged $<13$ years (all children studied were in this age group at diagnosis).[22] Time since ART initiation, therapeutic regimen at time of study, and ART-related adverse effects were also recorded from histories.

In-depth interviews were carried out with caregivers; more than one in some cases, for a total of 25 interviews. Caregivers'

Table 1: Variables

Clinical history review

Caregiver Interview

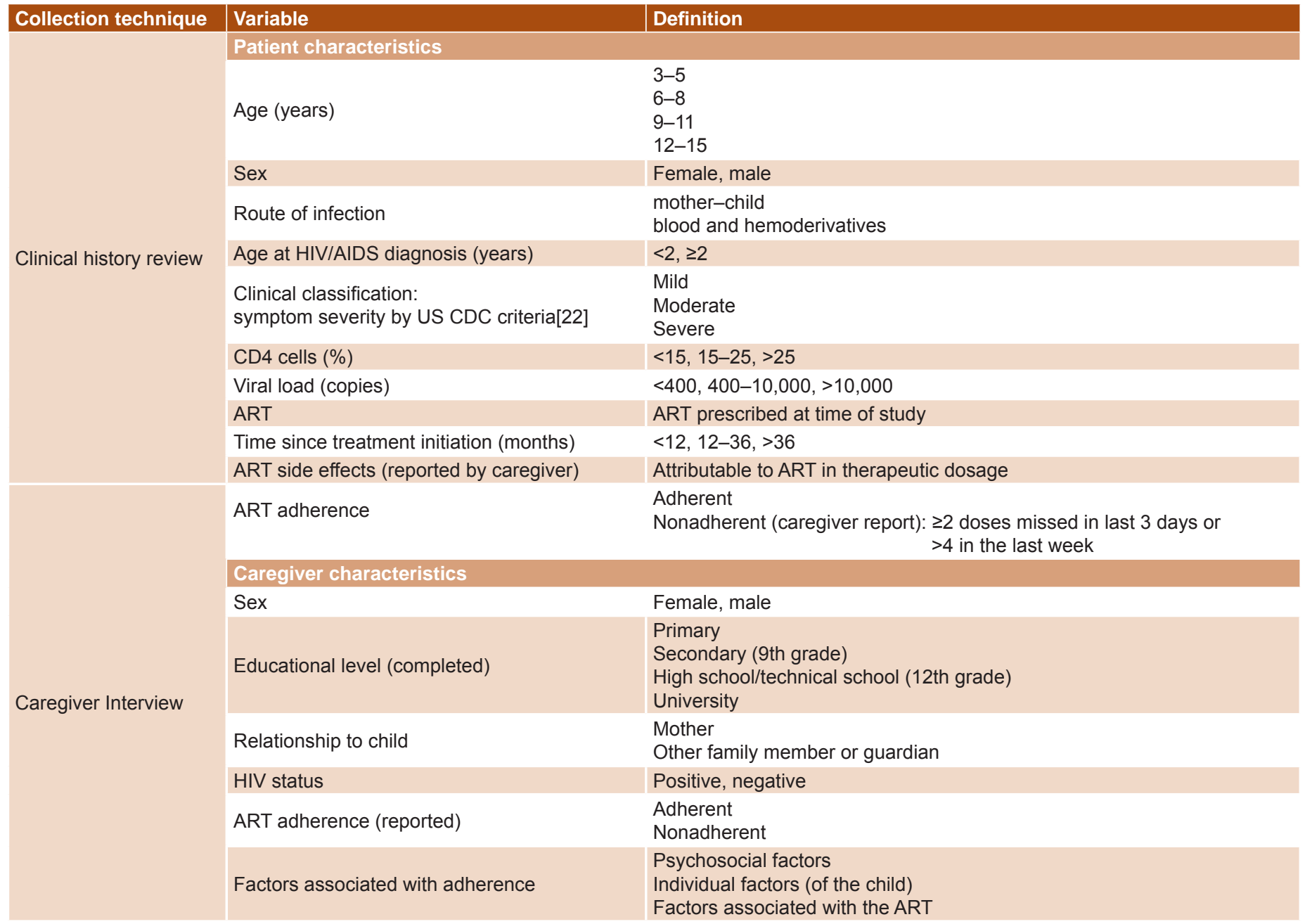

sociodemographic characteristics were included, displayed in Table 1. An interview guide was developed to explore factors related to treatment adherence: psychosocial (characteristics of the caregiver, family environment, and factors external to family), individual (of the child or adolescent), and factors related to ART (Table 2).

Analysis Absolute frequencies were calculated to describe the children and adolescents and their caregivers. Interviews were recorded and transcribed in their entirety and imported to the QRS NVivo 7 program for analysis. As a first step, information was grouped according to factors studied related to adherence (psychosocial factors, individual factors of the child or adolescent and ART factors). Later, comparisons were made that took into account age group and the child's ART adherence as reported by the caregiver. To improve internal validity, the authors discussed partial results to the extent that doing so advanced the analysis.

Ethics The IPK ethics committee approved this study. Written informed consent to participate was obtained from the primary caregivers and adolescents. Information confidentiality was assured during the entire process.

RESULTS Table 3 presents the characteristics of the children and adolescents. The predominant age group was 6-8 
Table 2: Psychosocial, individual and treatment factors assessed in relation to antiretroviral adherence

\section{Psychosocial factors}

Caregiver

Personal experience with ART

Opinion of treatment

Adherence history

Self-reported health status

Hospitalizations over the last year

Perception of physical or psychological obstacle to fulfilling caregiver role

Family

Family composition

Role of family members in treatment administration

Communication about the diagnosis within family

\section{Extrafamilial factors}

Other perceived social supports for ART administration

Formal support networks acknowledged by caregiver

\section{Individual factors}

Role assumed by patient in treatment administration

Patient's knowledge about diagnosis and treatment

\section{Factors associated with ART}

Regime, formulation and dose

Familiarity with the antiretroviral prescription

Reports of adverse symptoms attributable to antiretrovirals

Type of adverse symptoms reported

years (11/21); sex distribution was balanced. Mother-child transmission was the most frequent route of infection. In 11 children, diagnosis with HIVIAIDS infection occurred before age 2 years. Only one patient had begun ART less than one year before the study. In 14 of the children, CD4 values were $>25 \%$ and viral load was $<400$ copies $/ \mathrm{mL}$. The therapeutic combination of D4T+3TC+NEV was the most commonly prescribed (16/21). Nonadherence was found in 4 cases ( 2 adolescents and 2 children aged 9-11 years).

Table 4 presents characteristics of the primary caregivers. Mothers were the main caregivers for $19 / 21 ; 17$ of these mothers were living with HIVIAIDS. In only one case the father was the primary caregiver, and one girl was under the care of a guardian because both parents had died of AIDS. The majority of caregivers had completed at least secondary school (grade 9). One of the two caregivers who had completed only primary school was caring for a child infected through transfusion of blood or hemoderivatives.

\section{Psychosocial factors}

Caregivers Personal experience with ART and disease evolution in caregivers living with HIVIAIDS was an important factor in children's adherence. In the cases of one child and two adolescents who were nonadherent, their mothers were their caregivers and were also living with HIVIAIDS. The mothers' nonadherence was verified; they took little responsibility for their own adherence and missed followup appointments. Mothers living with HIVIAIDS who had adherent children reported different experiences; they showed concern for their own illness, actively seeking information about the disease and treatment advances.

The caregivers of the two children infected through blood or hemoderivative transfusion described managing the children's
Table 3: Characteristics of pediatric HIVIAIDS patients $(n=21)$

\begin{tabular}{|l|r|}
\hline Variable & $\mathbf{n}$ \\
\hline Age group & 4 \\
\hline 3-5 years & 11 \\
\hline $6-8$ years & 4 \\
\hline $9-11$ years & 2 \\
\hline $12-15$ years & \\
\hline Sex & 11 \\
\hline Female & 10 \\
\hline Male &
\end{tabular}

Route of infection

\begin{tabular}{|l|l} 
Mother-child transmission & 19
\end{tabular}

Blood or hemoderivatives 2

Age at HIVIAIDS diagnosis

$\geq 2$ years $\quad 11$

Clinical classification

Mild

10

Moderate 4

\begin{tabular}{l|l}
\hline Severe & 7
\end{tabular}

Time since treatment initiation

$<12$ months

1

12-36 months

$>36$ months $\quad 17$

ART prescribed

$\mathrm{D} 4 \mathrm{~T}+3 \mathrm{TC}+\mathrm{NEV}$

$\mathrm{AZT}+3 \mathrm{TC}+\mathrm{NEV}$

$A Z T+3 T C+E F V$

$\mathrm{D} 4 \mathrm{~T}+3 \mathrm{TC}+\mathrm{NEF}$

$3 \mathrm{TC}+$ Tenofovir+Kaletra

ART side effects

Yes

\begin{tabular}{|l|l|} 
No & 19
\end{tabular}

Adherence

Adherent

Nonadherent

3TC: lamivudine

D4T: stavudine

NEV: nevirapine

ART: antiretroviral therapy $\quad$ AZT: zidovudine EFV: efavirenz

NEF: nelfinavir

Table 4: Characteristics of primary caregivers of pediatric HIVIAIDS patients $(n=21)$

Variable

Sex

Female

Male

Relationship to child

Mother

Other family member or guardian

2

HIV status

Positive

Negative

Educational level (completed)

Primary

Secondary (9th grade)

Preuniversity/technical (12th grade)

University 
treatment as difficult, but only one of them had problems maintaining adherence (despite receiving support from outside the family). Only one girl lived with a guardian, due to the death of her parents; the guardian used the parents' deaths and the possibility of the girl's own death to urge her to remain adherent.

Two caregivers demonstrated concern that their own health status could interfere with their ability to care for the child. However, neither of them had been hospitalized in the year prior to the study. Emotional symptoms were more frequent among caregivers of nonadherent children. The caregiver of one nonadherent adolescent reported sadness and anxiety, but had abandoned psychological care and discontinued ART.

One caregiver acknowledged not feeling able to care for the child because he needed more care than she was physically able to provide, because of her own ill health. In this case, the family played an important role in ensuring treatment adherence, as illustrated by the following quote:

"I'm awaiting surgery now and I don't feel well. He is very restless. I know that's normal for his age, but I can't keep an eye on him all the time. That's why I need help. Sometimes I can't even take him to his doctor's appointments; my husband has to take him." (Caregiver of an adherent boy aged six years)

Families The mothers responsible for treatment of 19 of the children and adolescents also provided their families' main economic and emotional support. Only three families had both parents living at home. Grandmothers also played a fundamental role in taking care of the children, in two cases serving as primary caregivers and in at least four cases playing an important role in ART administration. As a rule, however, fathers were not proactive in the children's care in the families studied, except as a source of treatment support. Fathers had direct responsibility for treatment in only two cases, but only one father lived with the child. The fathers of the four nonadherent patients did not live with their children and took little responsibility for treatment.

Eleven caregivers of children and adolescents who acquired the disease through mother-child transmission reported that only a small group of people, including close family members and a few friends, were aware of either the children's or their own HIVIAIDS diagnosis.

Extrafamilial factors Caregivers of 18 children and adolescents did not consider it necessary to share the child's diagnosis with the school, despite the fact that school plays an important role at this stage in children's lives and has a major influence on their development and care. In only three cases did the school know the diagnosis of the children (two of whom were nonadherent), but did not have any responsibility for ART administration. In two cases, health professionals (the family doctor and nurse) assumed a fundamental role in treatment, preparing and administering antiretroviral doses and accompanying the children to specialist appointments. However, the health team did not completely replace family support, allowing for potential gaps in adherence, as the following quote illustrates:

"I know about the treatment, but the nurse comes to give it to him in the morning, and in the evening. Look, I know how to do it, but she takes care of sending the syrup to be prepared and she also administers it." (Caregiver of a nonadherent boy aged six years)

\section{Individual patient factors}

The role assumed by the children and adolescents in managing treatment was related to their age and was influenced by their relationships with their caregivers and whether caregivers assumed responsibility for dose administration. For children under nine years old, caregivers agreed that responsibility for treatment administration was theirs. However, beyond that age, caregivers transferred treatment responsibility to the children or adolescents, not always correlating with the youth's emotional maturity to take on the task. The caregivers of the two adolescents gave the youths more independence from both the caregivers themselves and from the family for ART administration. For these youths, caregivers reported missed doses, irregularities in timing of doses, and missed appointments with specialists, as this comment illustrates:

"I can't do anything. He takes the medications when he wants to. He should take them in the morning before going to school and at night, but that depends, because he forgets. He starts watching TV or doing other things. Me, what can I do? Nothing. It's his problem. I close the door to my room and he stays up doing his own thing. He has to take the medications; I've already told him so." (Caregiver of a nonadherent adolescent boy aged 13 years)

The mother of one girl assigned the child responsibility for remembering and preparing the medication for both herself and the child, failing to provide adequate oversight. This did not assure adherence:

"My daughter and I have a pillbox. My daughter organizes the pills for the week. She has an alarm programmed in her cell phone to remind her to take her medications, and she is the one who reminds me, sometimes, to take my medications too." (Caregiver of a nonadherent girl aged 11 years)

In general, caregivers reported speaking little with their charges about the disease. Only six had spoken explicitly with the children about their diagnosis. Seventeen caregivers were afraid to talk with them about HIVIAIDS, because they felt unprepared, mentioning reasons such as having to talk about their own disease and having to explain how the disease is transmitted. The following quote provides an example:

"He has never asked why he takes medications, which is why I haven't talked with him about his diagnosis. I still don't know what I'm going to do when that time comes. I'm very afraid of what he might think of me if he finds out that I am also sick." (Caregiver of an adherent boy aged nine years)

The three nonadherent children and adolescents infected by mother-child transmission were aware of their own diagnosis and that of their caregivers. They had spoken with their children about their disease and treatment, but this apparently did not contribute to successful ART adherence.

Families developed strategies to respond to adherence challenges and to integrate antiretroviral doses into their daily routines. The most commonly mentioned strategies were use of visual reminders and alarms. Caregivers of the two adherent children aged 9-11 years described a collaborative relationship in preparing and taking medications, which may have contributed to adherence success and to reinforcement of behaviors and incorporation into daily life, as illustrated by the following quote: 
“We take our medications together. She doesn't know what the tablets are called, but she recognizes them by the bottles and knows the quantities she needs to take from each bottle. She and I prepare the doses together. She never misses a dose. She knows that if I'm not home, her grandmother will remind her." (Caregiver of an adherent girl aged nine years)

\section{Factors associated with ART}

All caregivers reported having received information about HIVI AIDS, disease progression and treatment. In addition, they had participated in decisions regarding the child's treatment and were aware of side effects.

In terms of regimen, formulation and dose, no caregiver reported having declined treatment for the child when it was indicated. Caregivers of adherent children found administration of the medication in two doses per day to be conducive to treatment adherence. Two doses were associated with better integration into children's and caregivers' routines, especially because children did not need to take antiretrovirals at school and so it did not interfere with school activities. This advantage was mentioned by some of those interviewed:

"She takes her medications early, at 7 AM with breakfast, and later at night with dinner. Luckily, she doesn't have to take any during school. There, they don't know that she is sick, which is why taking medications at school would be a problem." (Caregiver of an adherent girl aged eight years)

For nonadherent children and adolescents, dosage frequency was not mentioned as a contributing factor to nonadherence.

ART side effects were not associated with nonadherence in these children. Side effects were rare and associated with specific formulations. The caregiver of one boy mentioned only nausea as a symptom, which he associated with a syrup. This led to changing the medication to tablets to facilitate adherence:

"He takes his medications well. I can never give him the liquid one. He doesn't like it-it makes him want to vomit-but he takes the tablets well. He takes his medications twice a day. I always give them to him. If I'm not home, my mother does." (Caregiver of an adherent boy aged nine years)

\section{DISCUSSION}

The results show the complexity of achieving adherence in this age group. The high adherence rates observed are consistent with other results based on caregiver reports. $[9,15,17]$ Nonadherence was associated primarily with psychosocial factors, such as the caregiver's assumption of responsibility while grappling with his or her own HIV diagnosis, psychological symptoms in the caregiver, perceived difficulties with family and extrafamilial support, and factors pertaining to the child or adolescent, such as age related to the level of responsibility assumed for treatment administration.

However, given the small study cohort, these results should be interpreted with caution. (A much larger study was not possible at the time of our research, since only 31 children and adolescents were living with HIVIAIDS in Cuba.) In addition, adherence assessment was based on caregiver reports, considered by some authors to be imprecise and given to overestimating adherence. $[10,17]$ Nonetheless, a study strength was the relationship between participants and their health care team, which continues longitudinal followup of these children and adolescents from the time of diagnosis. This contributed to greater objectivity in assessing adherence.

In contrast with other studies,[12,16,17] the caregivers did not mention factors related to access, treatment complexity or side effects as impediments to successful adherence. However, our results showed that difficulties in achieving adherence increased with age, coinciding with findings of other studies,[16,18,23] in which adolescents were assigned treatment responsibilities that they could not successfully handle. Similar results are seen in studies of treatment for other chronic illnesses, such as asthma, where adolescence was associated with decreased adherence.[24] For the two nonadherent children and the two nonadherent adolescents in the study, the medical team provided information and guidance to the caregivers, suggesting strategies to facilitate adherence and reinforcing adherence successes.

Psychological adaptation by families, especially by the primary caregiver, is an important factor in treatment adherence.[16,24] Our study reaffirmed the leadership role of the caregiver in achieving ART adherence in pediatric patients, as well as the influence of the caregiver's own adherence, in successful treatment of children and adolescents, both short and long term.

For children who acquired the disease through mother-child transmission, Williams indicated that treatments administered by a guardian or a family member not living with HIV showed a higher probability of adherence. Williams offers a possible explanation for this finding: the health status and the quality of life of these caregivers are less compromised by their own burden of disease. [25] Other authors believe that the absence of both parents can be associated with lower adherence, suggesting that parents play an important role in treatment administration.[17] In our study, from the perspective of the caregivers interviewed, the paternal figure did not play an important role in treatment adherence. On the other hand, the relationship between being an orphan and adherence could not be assessed because it applied to only one child, who lived with a guardian and was adherent.

Incorporating treatment into routine activities provided important reinforcement to boost adherence in these children and adolescents, consistent with findings of other authors, who reported that incorporating strategies for remembering doses and reducing dose frequency to twice daily were key factors in facilitating treatment adherence.[15,16,26]

Caregivers' reluctance to talk about their own illness and that of the child outside the family suggests a concern about stigma. This is consistent with results reported by other authors, who found that the anticipated stigma could represent a potential barrier to success of adherence strategies.[16,26]

\section{CONCLUSIONS}

This study provides initial insight into ART adherence and related factors for Cuban children and adolescents living with HIVIAIDS, confirming a high level of treatment adherence and the importance of the caregiver and the family for treatment success. The factors identified can contribute to an intervention framework for assessment and specialized interventions to optimize pediatric ART adherence. - 1 - 


\section{REFERENCES}

1. UNAIDS [Internet]. Geneva: UNAIDS; c2014. Epidemic Update; 2010 [cited 2010 Apr 4]. Available from: http://www.unaids.org/en/HIV_data/ epi20

2. Vreeman RC, Nyandiko WM, Ayaya SO, Walumbe EG, Marrero DG, Inui TS. The perceived impact of disclosure of pediatric HIV status on pediatric antiretroviral therapy adherence, child well-being, and social relationships in a resource-limited setting. AIDS Patient Care STDS. 2010 Oct;24(10):639-49.

3. World Health Organization [Internet]. Guidelines on HIV and infant feeding 2010. Geneva: World Health Organization; 2011 [cited 2011 Jun 20]. 58 p. Available from: http://whqlibdoc.who.int/publi cations/2010/9789241599535_eng.pdf

4. Brady MT, Oleske JM, Williams PL, Elgie C, Mofenson LM, Dankner WM, et al. Declines in mortality rates and changes in causes of death in HIV-1-infected children during the HAART era. J Acquir Immune Defic Syndr. 2010 Jan;53(1):86-94

5. Sutcliffe CG, van Dijk JH, Bolton C, Persaud D, Moss WJ. Effectiveness of antiretroviral therapy among HIV-infected children in sub-Saharan Africa. Lancet Infect Dis. 2008 Aug;8(8):477-89.

6. Harrigan PR, Hogg RS, Dong WW, Yip B, Wynhoven B, Woodward J, et al. Predictors of HIV drug-resistance mutations in a large antiretroviral-naïve cohort initiating triple antiretroviral therapy. J Infect Dis. 2005 Feb 1;191(3):339-47.

7. Lindsey JC, Malee KM, Brouwers P, Hughes MD; PACTG 219C Study Team. Antiretroviral therapy before and after the introduction of protease inhibitor-based highly active neurodevelopmental functioning in HIV-infected infants and young children. Pediatrics. 2007 Mar;119(3):e681-93.

8. Resino S, Bellón JM, León JA, Resino R, Muñoz MA; Grupo Español de Infección Pediátrica VIH. Carga viral plasmática en niños infectados por el virus de la inmunodeficiencia humana que reciben tratamiento antirretroviral de gran actividad. Med Clin (Barc). 2007 Jan 20;128(2):49-51. Spanish

9. Vreeman RC, Wiehe SE, Pearce EC, Nyandiko WM. A systematic review of pediatric adherence to antiretroviral therapy in low- and middleincome countries. Pediatr Infect Dis J. 2008 Aug:27(8):686-91.

10. Martin S, Elliott-DeSorbo DK, Calabrese S, Wolters PL, Roby G, Brennan T, et al. A comparison of adherence assessment methods utilized in the United States: perspectives of researchers, HIV-infected children, and their caregivers. AIDS Patient Care STDS. 2009 Aug;23(8):593-601.
11. Simoni JM, Montgomery A, Martin E, New M, Demas PA, Rana S. Adherence to antiretroviral therapy for pediatric HIV infection: a qualitative systematic review with recommendations for research and clinical management. Pediatrics. 2007 Jun;119(6):e1371-83.

12. Muyingo SK, Walker AS, Reid A, Munderi P, Gibb DM, Ssali F, et al. Patterns of individual and population-level adherence to antiretroviral therapy and risk factors for poor adherence in the first year of the DART trial in Uganda and Zimbabwe. J Acquir Immune Defic Syndr. 2008 Aug 1;48(4):468-75.

13. Ministry of Public Health (CU). Plan estratégico nacional ITS/VIH/SIDA [Internet]. Havana: Ministry Public Health (CU); 2009 [cited 2011 Jun 20]. 34 p. Available from: http://files.sld.cu/sida/ files/2011/08/informacion_practica_para_la _atencion_integral_a_pvs-2009.pdf. Spanish.

14. Aragonés $C$, Sánchez $L$, Campos J, Pérez J. Antiretroviral therapy adherence in persons with HIVIAIDS in Cuba. MEDICC Rev [Internet]. 2011 Apr [cited 2012 Jun 20];13(2):17-23. Available from: http://www.medicc.org/mediccreview/ index. php? issue $=16 \&$ id $=192 \& a=v a$

15. Merzel C, VanDevanter N, Irvine M. Adherence to antiretroviral therapy among older children and adolescents with HIV: a qualitative study of psychosocial contexts. AIDS Patient Care STDS. 2008 Dec;22(12):977-87.

16. Fetzer BC, Mupenda B, Lusiama J, Kitetele F, Golin C, Behets F. Barriers and facilitators of adherence to pediatric antiretroviral therapy in a Sub-Saharan setting: insights from a qualitative study. AIDS Patient Care STDS. 2011 Oct:25(10):611-21.

17. Davies MA, Boulle A, Fakir T, Nuttall J, Eley B. Adherence to antiretroviral therapy in young children in Cape Town, South Africa, measured by medication return and caregiver self-report: a prospective cohort study. BMC Pediatr. 2008 Sep 4;8:34.

18. Vaz LM, Eng E, Maman S, Tshikandu T, Behets F. Telling children they have HIV: lessons learned from findings of qualitative study in SubSaharan Africa. AIDS Patient Care STDS. 2010 Apr;24(4):247-56.

19. Steele RG, Grauer D. Adherence to antiretroviral therapy for pediatric HIV infection: review of the literature and recommendations for research. Clin Child Fam Psychol Rev. 2003 Mar;6(1):17-30.

20. Llabre MM, Weaver KE, Durán RE, Antoni MH, McPherson-Baker S, Schneiderman N. A measurement model of medication adherence to highly active antiretroviral therapy and its relation to viral load in HIV-positive adults. AIDS Patient Care STDS. 2006 Oct;20(10):701-11.

21. Patton $M Q$. Qualitative research and evaluation methods. 3rd ed. California: Sage Publications; 2001 Oct 31. 688 p.

22. Centers for Disease Control and Prevention. 1994 revised classification system for human immunodeficiency virus infection in children less than 13 years of age. MMWR [Internet]. 1994 Sep 30 [cited 2012 Jun 20];43(RR-12):1-10. Available from: http://www.cdc.gov/mmwr/PDF/ rr/rr4312.pdf

23. Kikuchi K, Poudel KC, Muganda J, Majyambere A, Otsuka K, Sato T. High risk of ART nonadherence and delay of ART initiation among HIV positive double orphans in Kigali, Rwanda. PLoS ONE. 2012;7(7):e41998

24. Burgess SW, Sly PD, Morawska A, Devadason SG. Assessing adherence and factors associated with adherence in young children with asthma. Respirology. 2008 Jun;13(4):559-63.

25. Williams PL, Storm D, Montepiedra G, Nichols S, Kammerer B, Sirois PA, et al. Predictors of adherence to antiretroviral medications in children and adolescents with HIV infection. Pediatrics. 2006 Dec;118(6):e1745-57.

26. Marhefka SL, Koenig LJ, Allison S, Bachanas P, Bulterys $M$, Bettica $L$, et al. Family experiences with pediatric antiretroviral therapy: responsibilities, barriers, and strategies for remembering medications. AIDS Patient Care STDS. 2008 Aug;22(8):637-47.

\section{THE AUTHORS}

Marta Castro Peraza (Corresponding author: martac@ipk.sld.cu),psychiatrist with a master's degree in social epidemiology. Associate professor, Pedro Kourí Tropical Medicine Institute (IPK), Havana, Cuba.

Ida González Núñez, neonatologist with a doctorate in medical sciences. Consulting professor, IPK, Havana, Cuba.

Jorge Pérez Lastre, pediatrician with a master's degree in infectious diseases, IPK, Havana, Cuba.

Submitted: April 11, 2013

Approved for publication: November 2, 2014 Disclosures: None 